\title{
TEATRO COM BEBÊS, MOVIMENTOS ENUNCIATIVOS E ESTÉTICOS
}

\author{
Jader Janer Moreira Lopes ${ }^{\mathrm{i}}$
}

Luiz Miguel Pereira ${ }^{\text {ii }}$

\begin{abstract}
RESUMO: Este artigo é resultado de um dos encontros de pesquisa da tese de doutorado "Teatro com bebês, enunciações e vivências: Encontros da arte com a vida". Os objetivos estão vinculados aos estudos da infância e bebês, evidenciando a brincadeira cênica enquanto possibilidades enunciativas dos bebês. As atividades, esteticamente elaboradas, promoveram possibilidades dos bebês se enunciarem e, ao mesmo tempo, serem espectadores dos outros bebês que dividiam a cena. A oferta dessa ambientação cenicamente elaborada, propiciou o aparecimento dos processos de imitação, de reelaboração criadora, composto de movimentos irrepetíveis. A palavra engatinhar simboliza a potência desse teatro, que se evidencia a partir dos processos de inacabamentos e de inconclusões.
\end{abstract}

Palavras-chave: Estudos da Infância; Pesquisa com Bebês; Teatro com Bebês; Teoria HistóricoCultural; Estudos Bakhtinianos.

\section{THEATER WITH BABIES, ENUNCIATIVE AND AESTHETIC MOVEMENTS}

\begin{abstract}
This article is the result of one of the research meetings of the doctoral thesis "Theater with babies, enunciations and experiences: Encounters of art with life", whose objectives are linked to the studies of childhood and babies, showing a scenic play while the enunciative possibilities of babies. The activities, aesthetically elaborated, promoted the possibilities of babies to present themselves and, at the same time, be the spectators of other babies who sharedthe scene. The offer of such a scenically elaborated environment, proposed the occurrence of imitation process, creative rework, composed of unrepeatable movements. The word crawl symbolizes the power of this theater, which is evident from the processes of incompleteness and inconclusions.
\end{abstract}

Keywords:Childhood Studies; Research with Babies; Theatre with Babies; Historical-Cultural Theory; Bakhtinian Studies

Este artigo é um fragmento do resultado da pesquisa de doutorado realizada pelo Programa de Pós-graduação em Educação da Universidade Federal Fluminense defendida em 2018. O encontro com os bebês ocorreu na Escola Nossa, em Niterói, e aqui apresentamos o quinto dos seis encontros que realizamos.

As enunciações humanas, as suas relações sociais, afetivas, espirituais e corporais podem ser produzidas também em cronotopos específicos, dada a condição individual e coletiva dos sujeitos e de suas vivências.

2020 Bargas; Ayoub; Assaritti, Scarazzatto, Assis. Este é um artigo de acesso aberto distribuído sob os termos da Licença Creative Commons Atribuição Não ComercialCompartilha Igual (CC BY-NC-4.0), que permite uso, distribuição e reprodução para fins não comerciais, com a citação dos autores e da fonte original e sob a mesma licença 
O gênero "teatro com bebês" possibilita a produção de cronotopos e narrativas estéticas, propondo atividade cênica a partir de alguns conceitos que irão viabilizar a participação dos bebês nessa revolução no conceito de teatro, o de dramaturgo-sacerdote.

O primeiro dramaturgo, na verdade, começou como jogral e mago. Mas gradualmente levou todo o universo de experiências e conhecimentos para o seu campo. O homem primitivo era um mimo acabado e uma criatura dada às práticas lúdicas. Desde o início foi um imitador que partilhava esse atributo com os animais superiores, mas ultrapassava-os na flexibilidade de seu corpo e voz, na desenvolvida consciência de sua vontade e na capacidade de ordenar o seu cérebro. Também brincava como seus irmãos animais, descarregando através desse meio sua vitalidade física. Onde quer que o teatro floresça, o homem volta a ser, não caindo em apologia, um animal superior ou uma criança imitando a criatura-mundo e desfrutando do prazer igualmente fundamental de brincar com a ajuda de todas as suas faculdades, desde o mais elementar movimento físico aos mais elaborados vôos da fantasia (GASSNER, 1991, p. 4).

No advento da história do teatro, percebemos a exclusão dos bebês de quaisquer participações até o final do século XX na Europa, quando algumas companhias italianas começaram a propor um teatro para bebês, uma ideia que está tomando corpo com atividades em vários países, inclusive no Brasil (PEREIRA, 2014). A citação acima exemplifica com clareza a relação das crianças, e aqui nos referimos aos bebês com idade até três anos, com o prazer de brincar, com a imitação, com os processos imaginativos, marcas fundantes numa proposta do teatro com bebês.

Podemos falar que o teatro com bebês é um movimento embrionário que tende a se proliferar como uma possibilidade na formação de professores, se materializando no campo da arte na Educação Infantil.

A repetição e a imitação podem ser consideradas as ações mais evidentes na atividade proposta. "Al hablar de la imitación no nos referimos a uma imitación mecânica, automática, sin sentido, sino a uma imitación racional, baseada na comprensión de la operacion intelectual que se imita" (VIGOTSKI ${ }^{\mathrm{iii}}, 2006$, p. 264). Todos esses movimentos foram atos de suas enunciações, de suas presenças no mundo, cada um vivenciando seus momentos de desenvolvimento humano.

A imitação, no teatro com bebês, aparece como um movimento das crianças numa perspectiva de criação. Fazemos relação da imitação com o drama. Embora não esteja discutindo o conceito de drama, é oportuno lembrar as crises ou revoluções na periodização das idades (VIGOTSKI, 2006). Essa variável dramática aparece enquanto ação das crianças. Conquanto a 
palavra tenha múltiplos significados, usaremos aqui com significado de ação, observando a sua origem em grego drâma.

Outra contribuição importante para o debate sobre o drama vem de Vigotski no texto "A criação teatral na idade escolar" em que afirma:

A criação teatral da criança, ou a dramatização, é a que está mais próxima da criação literária infantil. Juntamente com a criação verbal, a dramatização, ou a encenação teatral, representa o tipo de criação infantil mais frequente e difundido. Isso é compreensível porque ela está mais próxima da criança, o que se explica por dois momentos principais. Em primeiro lugar, o drama baseado na ação - na ação realizada pela criança - é mais íntimo, mais ativo e relaciona de maneira direta a criação artística com a vivência pessoal (VIGOTSKI, 2009, p. 97).

O drama em sua estrutura apresenta duas sensações, a de certa norma e sua violação (VIGOTSKI, 1999). Podemos identificar, no teatro com bebês, que uma norma é ofertar um espaço cênico que não favoreça a possibilidade de busca de aventuras além da proposta, se a criança desejar sair daquele espaço ela é atendida.

Podemos fazer aproximações do irrepetível com o movimento, enquanto caráter permanente das transformações. O movimento aparentemente repetitivo, mas que, com segunda ação, não é igual ao primeiro movimento, o devir para Deleuze.

DEVIR [devenir] é nunca imitar, nem fazer como, nem se conformar a um modelo, seja de justiça ou de verdade. Não há um termo do qual se parta, nem um ao qual se chegue ou ao qual se deva chegar. Tampouco dois termos intercambiantes. A pergunta 'o que você devém?' é particularmente estúpida. Pois à medida que alguém se transforma, aquilo em que ele se transforma muda tanto quanto ele próprio. Os devires não são fenômenos de imitação, nem de assimilação, mas de dupla captura, de evolução não paralela, de núpcias entre dois reinos (ZOURABICHVILI, 2005, p. 24).

Retomamos aqui alguns recortes de narrativas utilizadas nesta pesquisa para exemplificar o movimento, o irrepetível e a polifonia.

O exercício em promover uma atividade para os bebês, numa perspectiva de seus protagonismos, de suas vivências, de suas enunciações através de narrativas previamente pesquisadas, apoiados na possibilidade poética do teatro do oprimido, na teoria históricocultural, nos estudos bakhtinianos e nos estudos da infância, permite-nos pensar na produção de 
um teatro com bebês em que a brincadeira está em primeiro plano e a aposta nesse momento da vida.

Quando falamos de teatro envolvendo os bebês, reconhecemos, como já expresso anteriormente, que a brincadeira deve ser considerada o principal objetivo dessa atividade.

Inspiramo-nos no Pequeno Organon para o Teatro, de Bertolt Brecht (1898-1956), que faz um levantamento do teatro em seu tempo e apresenta pontos considerados importantes na perspectiva do teatro épico. A crítica à visão aristotélica a partir de sua poética, a crítica ao teatro burguês, a questão do distanciamento na interpretação. No item 35 do Organon, encontramos um texto que, guardando as devidas ressalvas, podemos identificar como uma possibilidade de um teatro com bebês:

\footnotetext{
Necessitamos de um teatro que não nos proporcione somente as sensações, as ideias e os impulsos que são permitidos dentro do respectivo contexto histórico das relações humanas (em que as ações se realizaram), mas também que empregue e suscite pensamentos e sentimentos que ajudem a transformação deste mesmo contexto (BRECHT, 1967, p. 197).
}

Assim, busca-se um teatro que suplante a ideia de espectador passivo, acostumado às sensações. A maioria dos bebês pesquisados se enuncia a partir do repertório ofertado, potencializando suas existências diante do outro e de si mesmos a partir da relação com os objetos e, consequentemente, da brincadeira que daí surgiu.

Entendemos que a transformação dos contextos, do teatro, das relações com os bebês, na Educação Infantil, requer estudos, disponibilidades para manter um projeto que tenha por princípio a valorização do ser humano em sua potência criadora.

Recorremos à estética do oprimido e fazemos aproximações dos bebês nesse conceito, devido à herança cultural de subalternidade, de pequenez, daqueles que não falam, estigma que a palavra infância carrega (KOHAN, 2008, p. 40).

TEATRO COM BEBÊS, QUINTO ENCONTRO, 23 DE AGOSTO DE 2017, QUARTAFEIRA, OCORRIDO ENTRE ÀS 14H30 MIN E 15 H.

Revista Interinstitucional Artes de Educar. Rio de Janeiro, V. 6, N.2-pág. 452-468 maio-agosto de 2020: "Bebês e crianças: cultura, linguagem e políticas" 
Toda pesquisa tem um espaço e tempo. Esta não é diferente. Foi realizada no espaço escolar da Educação Infantil da Escola Nossa (EN), lugar onde realizamos os encontros com os bebês.

A EN iniciou suas atividades no ano de 1987, em Niterói-RJ, com uma proposta associativa entre pais e professores denominada - Associação Comunitária de Educação e Cultura de Niterói (ACEC). A ideia comum do grupo apontava para uma escola onde o cotidiano se traduzisse num convite permanente de conviver, favorecendo um relacionamento vivo, participativo e inteligente, em permanente integração com a natureza, construindo coletivamente o conhecimento, descobrindo-se como pessoa (PROJETO POLÍTICO-PEDAGÓGICO EN, 2017).

Ocupava, no período em que realizamos a pesquisa, a função de coordenador pedagógico da Educação Infantil na Escola Nossa. A pesquisa de campo foi realizada durante o ano letivo de 2017, em fevereiro e concluída em setembro.

Nosso quinto encontro, realizado pela primeira vez na sala de teatro da Escola Nossa, ocorreu mais cedo, os anteriores ocorreram às $15 \mathrm{~h} 30 \mathrm{~min}$. Para a montagem do cenário, vestir figurino, fazer os combinados com as professoras (quem vai ficar comigo, quem filma), com as crianças (perguntar quem gostaria de participar) e me concentrar para a atividade levamos em torno de 2 horas. Mantivemos a ideia de cobrir duas paredes com o tecido transparente voal preto e forramos parte do piso do teatro fazendo a base da cobertura com algodão cru. (Figura 01).

\section{Figura 01 - Cenário visto de frente}

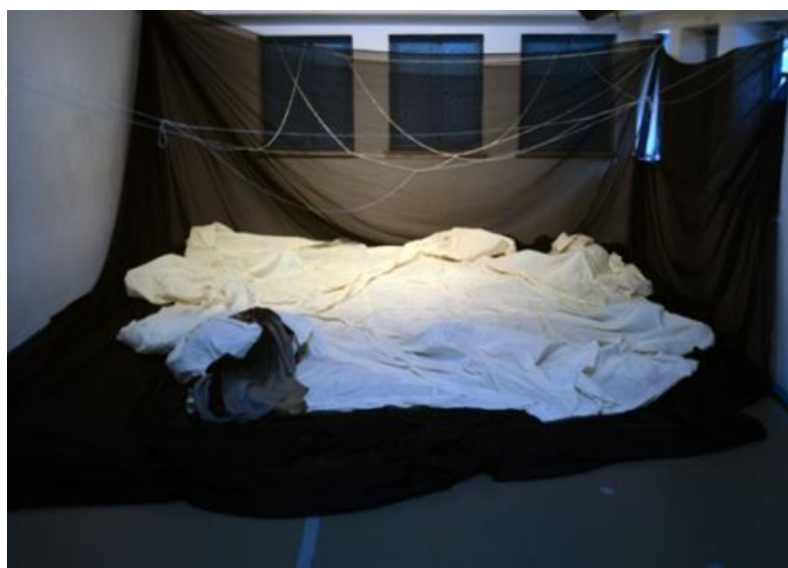

Fonte: Foto do autor

Escondemos algumas bolas de festas sob o tecido do piso, como fizemos no encontro anterior. Com barbante branco, construímos uma teia aérea um pouco mais alta que a criança de 


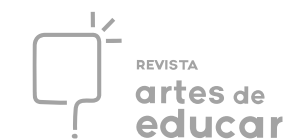

maior estatura, simbolizando a complexidade dos encontros, dos nós da rede. A mala verde com os adereços cênicos foi encoberta por uma manta cinza e preta e com parte do algodão cru. Também estreamos a iluminação com lâmpada dicroica, ambientando a temperatura da cena. $\mathrm{O}$ figurino foi o mesmo dos outros encontros ou seja: calça thai verde, $0 \mathrm{kl} 10$ bata indiana branca e meias brancas. Sem maquiagem.

Pensamos, no tempo de duração inspirados no tempo do teatro para bebês, num encontro com as crianças entre 20 e 30 minutos. Ao escrevermos as narrativas do encontro neste texto, optamos por diferenciar as falas dos bebês, que estão em negrito, das minhas, que estão em itálico.

As crianças que participaram foram: Natan, que demostrou vontade de participar pela primeira vez, anteriormente ficara curioso, mas não se sentira encorajado; Helena (quinta vez); Beatriz (quarta vez); Miguel Jorge (terceira vez) e Miguel Rebelo (terceira vez) ${ }^{\text {iv }}$.

Os bebês, ao nascerem, recebem um nome e serão conhecidos, doravante, a partir desse antropônimo. Chegam ao mundo e se deparam com um espaço/tempo já arquitetado, herdam toda herança cultural da humanidade.

Teatralizamos a existência, através de vivências estéticas com os bebês nomeados, pois, diferentemente do teatro para bebês, espaço em que são apenas espectadores, agora são protagonistas de suas enunciações e teatralidades. Assumimos uma posição política segundo a qual os bebês são seres da linguagem, que se forjam a partir dela e são, portanto, produtores de cultura. Optamos por assumir nesta pesquisa os nomes verdadeiros dos adultos e dos bebês, com base nos estudos bakhtinianos.

Esse encontro foi realizado com 42 dias de distância do nosso último encontro, em função do recesso escolar em junho/julho. Notamos que, nesse período, todas as crianças apresentaram visível desenvolvimento, sobretudo na comunicação. Participaram a prof. a auxiliar Claudinha, a prof. ${ }^{a}$ Dilma e a pesquisadora Aline, que fez as filmagens.

O roteiro consistia em apresentar o texto "Coisas inservíveis e a vida das crianças" de nossa autoria e, a partir daí, aguardar o interesse das crianças pela mala com objetos, abrindo-a simplesmente, deixando todos os objetos à mostra para eles pegarem quando e o que desejassem. Eu também pegaria alguns e continuaria a narrativa a partir do texto apresentado.

Recebemos as crianças na porta do teatro acompanhadas das professoras Claudinha e Dilma. As crianças foram entrando. Beatriz, imediatamente, interessou-se pela teia de cordão, 
ficou tocando-a como quem toca um instrumento. Miguel Jorge descobriu que, embaixo do algodão cru, havia bolas e foi falando:

\section{- A BOLA.}

Miguel Rebelo queria chegar até a mala. Assim, já foi tirando a manta que a cobria, assim como tentava tirar o algodão cru também. Sentei-me e comecei a falar:

- Vou contar uma história para vocês.

Natan, na sua primeira vez, permaneceu ao lado da professora Claudinha. Beatriz sentouse no cenário e Helena deitou-se, olhando para a teia.

Comecei a narrativa do texto "Coisas inservíveis e a vida das crianças" (PEREIRA, 2018, p.104). Enquanto fazia a narrativa, Helena se levantou e ficou brincando com a teia de cordão muito interessada. Um tempo depois, veio para perto ouvir a narração. Miguel Rebelo bateu com a mão três vezes na mala - PAM! PAM! PAM! -, pedindo para descobrir o mistério da mala encoberta. Natan, em sua primeira participação, ficou seguro do lado da prof. a Auxiliar Claudinha. Beatriz, que tinha muito afeto por Claudinha, inicialmente, ficou confortável deitada em seu colo de forma despojada. Rebelo, do lado da mala de objetos, e Miguel Jorge atento, principalmente quando esbarrou numa bola de festa que estava sob o tecido de algodão cru que cobria o piso do teatro. Beatriz se embolava no colo de Claudinha e no chão falando baixinho enquanto eu prosseguia com a narrativa:

- "Coisas feitas pela natureza, dia, noite, chuva, pedras, ventos, grama, água”

Em determinado momento, Helena voltou a brincar com a teia de cordão. Miguel Jorge e Miguel Rebelo aderiram imediatamente e começaram a puxar a rede com força, divertindo-se fazendo esse movimento. Continuei com a narrativa, comentando:

- E por isso que eu trouxe uma mala cheia de coisas.

Rebelo, apontando para a mala, disse:

- É ESSE?

Respondi que sim e descobri a mala. Miguel Jorge se dirigiu para perto dela falando:

\section{- OBAAAA.}

Natan, ainda tímido, permanecia em pé perto de Helena que continuava com as mãos no cordão. Beatriz continuava deitada no colo de Claudinha.

- O que será que tem aqui dentro? 
Miguel Jorge, tocando o zíper, abriu a mala de um lado, tentou abrir a tampa, mas não conseguiu. Bateu com as mãos e descobriu o outro zíper, mas não conseguiu ir até o final. Perguntei se queria ajudar e ele respondeu:

- QUÉ.

Esse ação chamou a atenção de Helena e Rebelo, que se aproximaram da mala. E a mala foi aberta. Miguel Rebelo imediatamente pegou o cesto dos desejos e me deu.

- Vou contar a estória de uma gente grande que não gosta mais disso, esqueceu. Aqui dentro tem um monte de segredos, de mistérios. Não pode deixar aberto, senão eles fogem. As pessoas guardam seus desejos aqui dentro - falei, dirigindo meu braço com o cesto até Beatriz que aceitou rindo.

Enquanto isso, Miguel Rebelo pegou a máquina fotográfica, que não funcionava, e Miguel Jorge o pneu, falando:

- É PAPÁ BIBI, É PAPÁ BIBI -fazendo referências ao carro de seu pai.

Helena pegou uma caixa que guardava a base do carrossel que já fora uma caixa de música. Ela deu corda e o som se espalhou pela sala. Peguei o candeeiro, acendi-o e falei:

- A luz!

Entreguei para Beatriz.

Miguel Jorge continuava falando, com o pneu na mão:

- BIBI PAPÁ.

Peguei a cuia de coco e levei-a à boca como se estivesse bebendo água e tossindo um pouco. Miguel Rebelo se interessou, pegou a cuia e me imitou, colocando-a na boca como se estivesse tomando água.

Miguel Jorge pegou o berrante, passando-me. Peguei-o e reproduzi o som. Beatriz brincava com a teia de cordão, Beatriz, com o candeeiro, perto de Claudinha, e Natan, muito tímido, pegou o cesto de desejos que Beatriz largara perto de Claudinha. Rebelo continuava na minha frente atenta a tudo o que estava acontecendo. Retirei a caixa que continha várias caixas dentro, colocando-a na minha frente. Miguel Rebelo se desinteressou e foi para a mala pegar uma pequena lanterna amarela. Nisso, Miguel Jorge veio destampar as caixas. Miguel Rebelo mostrou a lanterna para mim e me entregou-a. Iluminei os objetos e o meu rosto. Miguel Jorge pegou a lanterna de minha mão, iluminou seu olho e riu com sua atitude me imitando.

Revista Interinstitucional Artes de Educar. Rio de Janeiro, V. 6, N.2-pág. 452-468 maio-agosto de 2020: "Bebês e crianças: cultura, linguagem e políticas" 
Peguei a alfaia de dentro de mala e toquei. Beatriz se interessou imediatamente, pegandoa e começando a tocar. Mas, quando mostrei o som saindo da base do carrossel, ela veio buscar, guardando-a junto à alfaia. Mostrei a sineta e, mais uma vez, Beatriz pegou e começou a tocar. Miguel Jorge repetia insistentemente, com os dois pneus nas mãos:

\section{- PAPA BIBI!}

Miguel Rebelo pegou a pena de arara, passou um tempo com ela, devolvendo-a depois para dentro da mala e pegando as duas cuias de coco seco que ficou juntando. Beatriz tentou dar corda na base do carrossel para a música voltar a tocar. Natan continuava ao lado de Claudinha junto dos objetos que Beatriz pegara. Helena, em pé, passeava pelos caminhos da teia de cordão.

Peguei a pena de arara, imitei um som de arara e passei a pena em Miguel Jorge e Miguel Rebelo. Ambos riram do contato da pena com seus corpos. Entreguei a pena para Beatriz. Helena pegou o berrante com curiosidade.

Miguel Rebelo pegou o carrinho de madeira sem uma roda. Miguel Jorge perguntava pelo carrinho de madeira:

\section{- E O OTO?}

- Está ali - respondi, enganando-me, uma vez que o carrinho estava com Rebelo que levantou a mão com o carrinho e entregou para Miguel Jorge que falou:

\section{- BRIGADO.}

Ri com alegria infinita da delicadeza comunicativa deles. Gestos de solidariedade e gratidão. Retirei um cavaquinho um pouco corroído pelo tempo, com apenas duas cordas e desafinado.

- Foi abandonado por um músico, segundo ele, esse instrumento não servia para mais nada.

Comecei a tocar. Beatriz me pediu o instrumento, mas Miguel Jorge negociava com ela. O cavaquinho acabou ficando com ele. Ela, então, pegou o berrante, produzindo o som com ele na boca .Natan, que ainda se encontrava no mesmo lugar do início do encontro, pegou a máquina fotográfica. Miguel Jorge dedilhava as cordas do cavaquinho. Chamei a atenção com uma fala:

- E esse monte de coisas que os adultos já não gostam mais e a gente gosta, nós brincamos com elas, nos alegramos e contamos histórias a partir delas.

Peguei as duas bandas de coco seco e falei:

- E aqui ô, música.

Revista Interinstitucional Artes de Educar. Rio de Janeiro, V. 6, N.2-pág. 452-468 maio-agosto de 2020: "Bebês e crianças: cultura, linguagem e políticas" 
Comecei a tocar. Beatriz imediatamente se interessou e me pediu. Espalhei as caixas do meu lado. As crianças estavam falando baixinho suas palavras, seus textos, seus silêncios no contato com os objetos, enquanto eu era espectador de seus encontros, interesses e enunciações. Peguei a boneca andina na mala e falei:

- Uma boneca, lá da Cordilheira dos Andes, tão sozinha, ninguém quer pegar nela.

Beatriz se esforçava para chegar onde eu estava e para pegar a boneca.

- Ah, quer?

Ela conseguiu pegar a boneca. Miguel Rebelo pegou um espantalho de palha, passou-o carinhosamente no meu rosto e me entregou.

- Tem outro espantalho - falei, deitando-me no chão com os dois espantalhos.

- Tem um monte de coisas aqui, vamos brincar.

Miguel Jorge pegou o cavaquinho e, em pé, começou a tocá-lo de seu jeito. Miguel Rebelo tinha dois espantalhos nas mãos. Helena, em pé com a lanterna amarela, iluminava a pluma azul que estava na sua outra mão. Beatriz permanecia sentada perto de Claudinha com a boneca andina na mão e Natan com a máquina fotográfica.

Miguel Jorge se interessou pela lanterna para iluminar os pneus falando:

\section{- BIBI PAPÁ.}

Miguel Rebelo pegou o cavaquinho e começou a tocar, segurando-o em seu colo.

Natan, ainda com a máquina fotográfica, colocou-a sobre a alfaia. Beatriz falava baixinho.

- TEDITA - falou umas quatro vezes, enquanto Miguel Jorge pegava a lanterna.

Natan pegava o cesto de desejos com uma mão e na outra segurava a máquina fotográfica. Helena se interessou pela alfaia. Beatriz, com a boneca no colo, cantava uma cantiga numa língua ainda não entendida por mim, ninando a boneca, um instante de muita delicadeza. Miguel Jorge tropeçou no relevo de bola de festa, falando:

- A BOLA, A BOLA.

- Cadê a bola?

- A BOLA TÁ AQUI - responde Helena, pegando a bola e me mostrando.

Comecei a retirar as bolas do subsolo do cenário.

- Tem mais, vamos procurar? 
As crianças continuavam produzindo suas brincadeiras a partir da oferta de objeto, num arranjo cênico. Esse encontro na sala do teatro permitiu ouvir suas falas e seus silêncios. As falas para si, a partir dos objetos, foram principalmente de Beatriz e Natan. Já Miguel Jorge e Miguel Rebelo dirigiram suas falas para o outro. Helena ficou nesse entre-lugar entre ela e o outro.

Desfiz os relevos de bolas. Miguel Rebelo e Miguel Jorge riam, gostando de brincar com as bolas, enquanto os demais ficaram em torno de Claudinha, continuando suas conversas com os objetos. Provoquei-os, jogando bolas em cima deles.

- As coisas querem voltar para dentro da mala, quem pode ajudar?

Helena, sempre solícita e colaborativa, trouxe a boneca andina e colocou-a dentro da mala.

- Não precisa guardar as bolas.

Miguel Rebelo, felicíssimo com suas bolas, nem se interessou em ajudar a guardar as coisas inservíveis e falava:

$-\underset{A}{A} \mathbf{A}$ A A A A A A A A.

Natan e Beatriz continuavam ao lado de Claudinha com seus interesses. Miguel Jorge e Helena iam acomodando as coisas dentro da mala.

Helena juntou várias caixas e caminhou até a mala para guardá-las.

- Obrigado- falei, dirigindo-me para Beatriz:

- Você pode botar o cavaquinho dentro da capa?

Inicialmente, ela tentou guardar o cavaquinho com a parte maior do instrumento na parte do braço, ao contrário. Tentou várias vezes fazer com que o cavaquinho entrasse, mas não conseguiu. Perguntei-lhe se queria ajuda, ela falou que sim.

- É assim ó - falei, virando a capa ao contrário.

Depois de várias tentativas, ela conseguiu encapar o cavaquinho. Natan encontrou as bolas. Beatriz tirou a máquina fotográfica de suas mãos para guardar na mala. Ele, finalmente, levantou-se e foi atrás de Helena para ter de volta sua máquina. Silenciosamente se agarrou com ela e coreografaram um lindo bailado, cada um com suas intencionalidades enunciativas.

Helena foi se proteger com Claudinha e Natan foi para as bolas de festa. Miguel Jorge decidiu me ajudar, entregando as cuias dos cocos. Helena falou, com uma caixa na mão:

- TEM UMA.

Revista Interinstitucional Artes de Educar. Rio de Janeiro, V. 6, N.2-pág. 452-468 maio-agosto de 2020: "Bebês e crianças: cultura, linguagem e políticas" 
- Tem mais? Não? Então vamos bater palmas - agradeci-lhe, batendo palmas

Helena me acompanhava nas palmas. Beatriz comentava baixinho em sua língua misteriosa. Assim, encerramos o nosso teatro com muita alegria. Agradeci a todos e chamei-os para descermos, pois estava na hora de fazer o lanche. Rebelo me entregou o cesto dos desejos para guardar na mala apontando com o dedo e dizendo:

\section{- GUARDAR!}

Desse modo, guardando o cesto dos desejos, é que encerramos nosso encontro do dia.

Indubitavelmente, foi o encontro em que a poética esteve presente durante todo o tempo. $\mathrm{O}$ espaço do teatro com suas especificidades muito contribuiu para esse resultado. A oferta dos objetos, a ambientação cenográfica e a iluminação, as narrativas das crianças, seus silêncios, suas enunciações, suas intencionalidades de manter os objetos para si e de se solidarizarem promoveram essa possibilidade poética, o teatro com bebês.

Ao trazer o bebê para a atividade cênica, na perspectiva de sua enunciação, a atividade não é para bebês e, sim, com bebês, na perspectiva de seu protagonismo. Na concepção do teatro para bebês, evidencia-se uma perspectiva sensorial, portanto, o bebê é o receptor, ou seja, a plateia. No teatro desde os bebês, a partir dos bebês e teatro para primeira infância, a perspectiva é a mesma.

A tese que defendemos é uma possibilidade de teatro com bebês. Não invoco aqui o classicismo histórico do teatro, pois seria ingenuidade, mas outras possiblidades de adentrar nos conceitos teatrais e de propiciar uma produção estética em que os bebês sejam protagonistas, isto é, sejam atores e plateia ao mesmo tempo.

Apoiamos nosso referencial teórico a partir do texto inédito "Sobre o teatro infantil ${ }^{1}$, escrito em 1923 por Lev Semyonovich Vigotski, que sinaliza algumas questões que pontuam essa possibilidade, dentre elas que o teatro é uma brincadeira elevada.

[...] E mais: o teatro para crianças ou teatro das crianças. Numa palavra - para o adulto existe um monte de questões pedagógicas, artísticas, um monte de dificuldades e dúvidas insolúveis naquilo que é denominado teatro infantil [...] Porém, para a criança, está tudo decidido e tudo claro: o teatro para ela é uma brincadeira elevada (ou seja, duas vezes mais interessante), e não uma nova narrativa do conto que ela compreende sem a representação (VIGOTSKI, 1923, apud PEREIRA, 2018, p. 89) ${ }^{2}$

\footnotetext{
${ }^{1}$ Tradução do russo para o português e gentilmente cedido pela prof. ${ }^{a}$ Dra. Zoia Prestes para ser publicado na tese

"Teatro com bebês, enunciações e vivências: encontros da arte com a vida"

${ }^{2}$ Resenha de L. S. Vigotski publicada em Nach Ponedelnik, ${ }^{\circ} 35$, de 07.05.1923, p. 3.
}

Revista Interinstitucional Artes de Educar. Rio de Janeiro, V. 6, N.2-pág. 452-468 maio-agosto de 2020: "Bebês e crianças: cultura, linguagem e políticas" 
Portanto, em meados dos anos de 1920 do século XX, essas questões estavam sendo pensadas a partir dos estudos da teoria histórico-cultural. Assim, os bebês crianças do século XXI estão sendo contemplados com uma possibilidade de teatro que privilegia suas enunciações e, por conseguinte, seus protagonismos.

A vivência (perejivanie), conceito central da teoria histórico-cultural, promove perspectiva de pesquisa sobre o desenvolvimento social dos bebês. O desenvolvimento é um drama, no sentido do teatro grego, é transformador, algo que morre.

A vivência é uma unidade na qual, por um lado, de modo indivisível, o meio, aquilo que se vivencia está representado - a vivência sempre se liga àquilo que está localizado fora da pessoa - e, por outro lado, está representado como eu vivencio isso, ou seja, todas as particularidades da personalidade e todas as particularidades do meio são apresentadas na vivência, tanto aquilo que é retirado do meio, todos os elementos que possuem relação com dada personalidade, como aquilo que é retirado da personalidade, todos os traços de seu caráter, traços constitutivos que possuem relação com dado acontecimento. Dessa forma, na vivência, nós sempre lidamos com a união indivisivel das particularidades da personalidade e das particularidades da situação representada na vivência. Por isso, parece apropriado conduzir de maneira sistemática a análise do papel do meio no desenvolvimento da criança, conduzila do ponto de vista das vivências da criança, porque na vivência, como já coloquei, são levadas em conta todas as particularidades que participaram da determinação de sua atitude frente a uma dada situação (VIGOTSKI, 2010, p.686 -687. Grifos do autor).

Ao ofertarmos uma atividade cênica com os bebês, estamos, portanto, oferecendo uma possibilidade de suas enunciações através de suas vivências numa perspectiva de situação social de desenvolvimento em um meio esteticamente pensado para esses encontros.

1- A vivência se manifesta na qualidade de principal característica da situação social do desenvolvimento; elas refletem a unidade do "interno" e do "externo" no desenvolvimento. [...] 2- As vivências são a unidade afeto-intelecto [...] 3As vivências são uma unidade (indicador integrativo) de análise da consciência e do desenvolvimento da personalidade. [...] 4- A vivência leva ao desenvolvimento da personalidade; é fator e, ao mesmo tempo, a condição interna de uma neoformação (JEREBTSOV, 2014, p. 16-17).

A brincadeira, presente no teatro com bebês, é também um conceito chave da teoria.

A brincadeira da criança não é uma simples recordação do que vivenciou, mas uma reelaboração criadora de impressões vivenciadas. É uma combinação 
dessas impressões e, baseado nelas, a construção de uma realidade nova que responde às aspirações e aos anseios da criança. Assim como na brincadeira, o ímpeto da criança para criar é a imaginação em atividade (VIGOTSKI, 2009, p. 17).

Encontramos, nos estudos bakhtinianos, as aproximações teóricas que dialogaram com esta pesquisa do campo da linguagem.

O sentido correto e não falso de todas as questões antigas, relativas à interrelação de arte e vida, à arte pura, etc., é o seu verdadeiro pathos apenas no sentido de que a arte e vida desejam facilitar mutuamente a sua tarefa, eximir-se da sua responsabilidade, pois é mais fácil criar sem responder pela vida e mais fácil viver sem contar com a arte. Arte e vida não são a mesma coisa, mas devem tornar-se algo singular em mim, na unidade da minha responsabilidade (BAKHTIN, 2003, XXXIV).

Só foi possível assumirmos a arquitetônica deste texto a partir do alargamento de reflexões sobre outras possibilidades de fazer ciência, uma ciência outra ou heterociência, que nos possibilitou esse encontro da arte com a vida.

É um triste equívoco, herança do racionalismo, imaginar que a verdade [pravda] só pode ser a verdade universal [istina] feita de momentos gerais, e que, por consequência, a verdade [pravda] de uma situação consiste exatamente no que esta tem de reprodutível e constante, acreditando, além disso, que o que é universal e idêntico (logicamente idêntico) é verdadeiro por princípio, enquanto a verdade individual é artística e irresponsável, isto é, isola uma dada individualidade. [...] A verdade [pravda] do evento não é em seu conteúdo, uma verdade [istina], identicamente igual a si mesma; é, ao contrário, a única posição justa de cada participante, a verdade [pravda] do seu real dever concreto (BAKHTIN, 2010, p. 92 e 104).

O deslocamento para uma verdade pravda, que é a do mundo da vida, relativa ao acontecimento em si e às percepções que dele fazem os sujeitos envolvidos (GERALDI, 2012, p. 25), endereçou-nos para uma perspectiva de pesquisa que possibilita fazermos, junto com os bebês, um teatro com eles, olhando para a vida e para a arte de forma enviesada. Para que nos relacionássemos no ato estético, fomos ser e sendo ao mesmo tempo.

Os estudos sobre teatro com bebês estão embrionários. Esta pesquisa com as crianças da Escola Nossa fica aqui registrada, entretanto, a pesquisa continua e em qual perspectiva? Na continuidade dos estudos de crianças e infâncias, incluindo os bebês, na possibilidade de promover formação de professores no campo do teatro para a primeira infância e em prováveis cursos de extensão.

Revista Interinstitucional Artes de Educar. Rio de Janeiro, V. 6, N.2-pág. 452-468 maio-agosto de 2020: "Bebês e crianças: cultura, linguagem e políticas" 
A vocalização das palavras dos bebês na pesquisa é repleta de intencionalidades, de afirmação, negação, pertencimento, alegria, entusiasmo, desinteresse, receios. Assim, a partir de seu pertencimento, naquele espaço, o silêncio se presentifica e, na maioria das vezes, mediante a situação social de desenvolvimento de cada criança, vamos identificando as variáveis poéticas das suas existências.

Assim foram os encontros de pesquisa. Enquanto as palavras e as enunciações circulavam para todos os presentes, registrei-as a partir das filmagens. Atribuir sentidos, a partir das observações em vídeos gravados dos encontros de pesquisa, inevitavelmente, levou-me a fazer escolhas. Assim, de alguma maneira, deformei, através da escrita, as narrativas. Dentro de campo semântico, a tradução do que vivenciei, do que os bebês vivenciaram e aquilo a que assisti, alguma coisa escapou, ficando, na narrativa, as enunciações de suas vivências e de suas e minhas palavras.

Esta pesquisa ocorreu numa perspectiva de assumir os inacabamentos, as incertezas, os acasos e, sobretudo, as coisas inservíveis dos adultos e presentes na vida dos bebês.

O teatro com bebês tem, por princípio, o protagonismo dos bebês, como numa arquitetônica do ato, eu pelo outro, o outro com o outro e o outro por mim.

O princípio arquitetônico supremo do mundo real do ato é a contraposição concreta, arquitetonicamente válida, entre eu e o outro. A vida conhece dois centros de valores, diferentes por princípio, mas correlatos entre si: eu e o outro, e em torno destes centros se distribuem e se dispõem todos os momentos concretos do existir (BAKHTIN, 2010, p. 142).

O princípio de alteridade, a descentralização do eu, a ética, enquanto ato responsável, e o exercício da potência em também ser protagonista nesse ato criativo de enunciações são princípios importantes para produzir um teatro com bebês.

Defendemos que o teatro com bebês não se apoia em um modelo clássico de teatro adaptado e elaborado para os bebês, mas em uma constante recriação, que conecta o ato criador infantil com o ato criador dos adultos, seus corpos com os objetos e organização cênica, suas inquietudes com as nossas. O espaço e o tempo da "apresentação" tornam-se um espaço/tempo de criação.

O lócus está em criar a fronteira de um espaço e tempo que preexiste, para que, nela, as crianças possam inventar o mundo, o outro e inventar-se. Assim como o fazem com as coisas 
inservíveis, coisas novas, dando-lhes vida, as crianças recriam o texto prévio, escrevem um novo roteiro, desfazem a cena, para a vivência constante do inesperado.

Ao considerarmos que o teatro com bebês, enquanto um acontecimento, mesmo depois que a atividade termine, os bebês continuam criando interesses brincantes. Assim, não seria sensato, levando em consideração a poética das crianças, apresentar uma conclusão. Por outro lado, ao levarmos em consideração que a pesquisa sobre o teatro com bebês está iniciando sua trajetória enquanto arte, arte educação e com significativa possibilidade de se tornar habitué nas unidades de Educação Infantil, é prudente estabelecer seu cronotopo.

A palavra engatinhar simboliza a potência desse teatro, que se evidencia a partir dos processos de inacabamentos, de inconclusões. "A arte é antes uma organização do nosso comportamento visando um futuro, uma exigência que talvez nunca venha a concretizar-se, mas que nos leva a aspirar acima da nossa vida o que está por trás dela” (VIGOTSKI, 1999, p. 320).

\section{REFERÊNCIAS}

BAKHTIN, M..Estética da criação verbal. São Paulo. Martins Fontes, 2003.

. Para uma filosofia do ato responsável. Trad. Valdemir Miotello \& Carlos Alberto Faraco. São Carlos: Pedro \& João Editores, 2010.

BRECHT, B. Estudos Sobre o Teatro. Rio de Janeiro: Nova Fronteira, 1978.

Teatro Dialético. Rio de Janeiro. Civilização brasileira. 1967.

GASSNER, J. Mestres do Teatro I. Trad. e org. Alberto Guzik e J. Guinsburg. São Paulo: Ed. Perspectiva, 1991. (Coleção Estudos).

GERALDI, J. W. Heterocientificidade nos estudos linguísticos. In: Grupo de Estudos de Gêneros do Discurso - GEGe-UFSCar. Palavras e contrapalavras: enfrentando questões da metodologia bakhtiniana. São Carlos: Pedro \& João Editores, 2012, p 19 -39.

JEREBTSOV, S. G. - A cidade de L.S.Vigotski. Pesquisas científicas contemporâneas sobre instrução no âmbito da teoria histórico-cultural de L.S.Vigotski. VERESK - Cadernos Acadêmicos Internacionais. Brasília: UniCEUB, 2014.

KOHAN, W. O. Infância e Filosofia. In: SARMENTO, M.; GOUVEIA, M. C. (Orgs.) Estudos da Infância, Educação e Práticas Sociais.Coleção Ciências Sociais e Educação. Petrópolis, RJ: Vozes, 2008, p. 40-61. de 2020: "Bebês e crianças: cultura, linguagem e políticas" 
PEREIRA, L. M. Teatro com bebês, enunciações e vivências: encontros da arte com a vida. Tese (Doutorado em Educação) Universidade Federal Fluminense. Niterói, 2018.

Teatro com bebês, estreia de olhares. 2014. Dissertação (Mestrado em Educação)

Universidade Federal Fluminense. Niterói. 2014.

PRESTES, Z. R. Quando não é quase a mesma coisa: análise de traduções de Lev Semionovitch Vigotski no Brasil: Repercussões no campo educacional. 2010. Campinas, SP. Autores Associados, 2012. Coleção educação contemporânea.

VIGOTSKI, L. S. Obras Escogidas. Tomo IV: Psicología Infantil. Madri: Machado Libros, 2006.

Imaginação e Criação na infância.Trad. Zoia Prestes. São Paulo: Ática, 2010.

Quarta aula: a questão do meio na pedologia. Tradução de Márcia Pileggi Vinha.

Psicologia USP,São Paulo. 2010.

Psicologia da arte. Trad. Paulo Bezerra. São Paulo: Martins Fontes, 1999.

ZOURABICHVILI, F. O vocabulário de Deleuze. Tradução, André Telles. Centro interdisciplinar de estado em novas tecnologias de informação. Rio de Janeiro. 2004. Disponível $\mathrm{em}$ : http://escolanomade.org/wpcontent/downloads/deleuze-vocabulario-francoiszourabichvili.pdf. Acesso em: 12.out.2019.

\footnotetext{
${ }^{\text {i }}$ Professor do Departamento de Educação da Universidade Federal de Juiz de Fora (UFJF), Faculdade de Educação. Brasil. Doutor em Educação pela Universidade Federal Fluminense. E-mail: jjanergeo@gmail.com ORCID: http://orcid.org/0000-0003-3510-8647

ii Professordo ensino superior da Faculdade de Educação Tecnológica do Estado do Rio de Janeiro -FAETERJ -Três Rios- RJ.Brasil. Doutor em Educação ela Universidade Federal Fluminense. E-mail: luizmiguelp@gmail.com ORCID: http://orcid.org/0000-0001-6666-1627

iii Optamos por adotar a grafia do nome de Vigotski, embora tenha diferentes grafias nas traduções brasileiras. Prestes (2012) adota como melhor transliteração do russo para o português.

iv A pesquisa foi autorizada pelo comitê de ética da Universidade Federal Fluminense (UFF), vinculado à Plataforma Brasil. Parecer aprovado $n^{\circ}$ 2.574.705 e CAAE $n^{\circ}$ 81164817.3.0000.5243.

${ }^{v}$ Disponível em vídeo em: https://www.youtube.com/watch?v=yNFcWyzmePU\&t=57s
}

Revista Interinstitucional Artes de Educar. Rio de Janeiro, V. 6, N.2- pág. 452-468 maio-agosto de 2020: "Bebês e crianças: cultura, linguagem e políticas" 